\title{
8
}
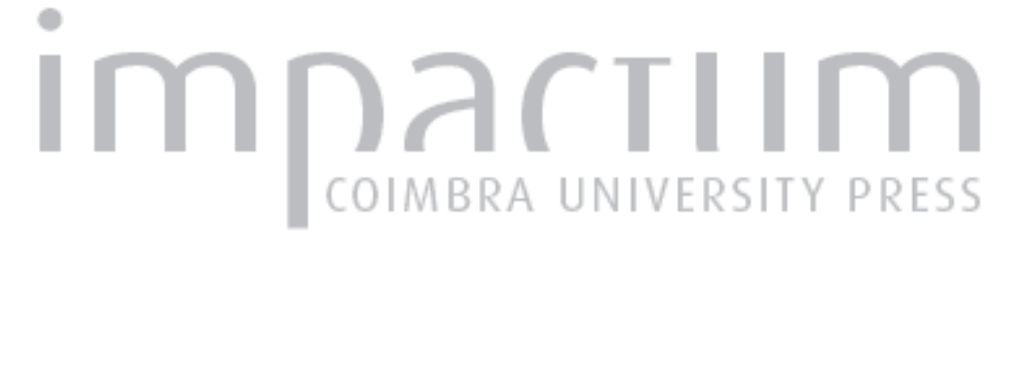

\section{O ponto da situação da Geografia Física no Brasil apresentado em livro}

\section{Autor(es): Rebelo, Fernando}

Publicado por: Associação Portuguesa de Riscos, Prevenção e Segurança

URL persistente:

URI:http://hdl.handle.net/10316.2/40058

DOI:

DOI:https://doi.org/10.14195/1647-7723_11_5

Accessed : $\quad$ 26-Apr-2023 15:38:05

A navegação consulta e descarregamento dos títulos inseridos nas Bibliotecas Digitais UC Digitalis, UC Pombalina e UC Impactum, pressupõem a aceitação plena e sem reservas dos Termos e Condições de Uso destas Bibliotecas Digitais, disponíveis em https://digitalis.uc.pt/pt-pt/termos.

Conforme exposto nos referidos Termos e Condições de Uso, o descarregamento de títulos de acesso restrito requer uma licença válida de autorização devendo o utilizador aceder ao(s) documento(s) a partir de um endereço de IP da instituição detentora da supramencionada licença.

Ao utilizador é apenas permitido o descarregamento para uso pessoal, pelo que o emprego do(s) título(s) descarregado(s) para outro fim, designadamente comercial, carece de autorização do respetivo autor ou editor da obra.

Na medida em que todas as obras da UC Digitalis se encontram protegidas pelo Código do Direito de Autor e Direitos Conexos e demais legislação aplicável, toda a cópia, parcial ou total, deste documento, nos casos em que é legalmente admitida, deverá conter ou fazer-se acompanhar por este aviso.

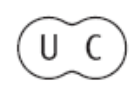


nas vertentes de longa secção rectilínea como as das arribas de São Jorge, ganharão certamente uma dimensão maior e de consequências imprevisíveis para jusante. A perda de base de apoio de um pavimento construído parcialmente sobre aterro, começando por fracturar o asfalto (fot. 6), poderá desencadeará um deslizamento rotacional que logo se transformará num movimento rápido de desabamento ou, havendo muita água disponível, num extenso fluxo de detritos.

A reabertura da estrada para a Fajã dos Cúberes demorou muito. Quinze dias depois, no concelho da Calheta, ao qual pertence aquela estrada, discutia-se o porquê da demora. Mas ainda seria necessário estudar bem o que tinha acontecido e prever o que poderia voltar a acontecer com a retirada dos grandes blocos depositados sobre a estrada. O rompimento precipitado do equilíbrio instável em que se encontravam levaria a novos movimentos. Foi, portanto, necessário recorrer a uma empresa com experiência neste tipo de ocorrências.

O movimento brusco de materiais pela vertente pode cortar estradas (como neste caso aconteceu), como pode terminar sobre uma fajã com a possibilidade de arrasar casas e de cobrir campos de cultivo. Se o detonador para o movimento for um sismo, então os desabamentos provocados poderão fazer aumentar a superfície de fajãs existentes ou até criar novas fajãs.

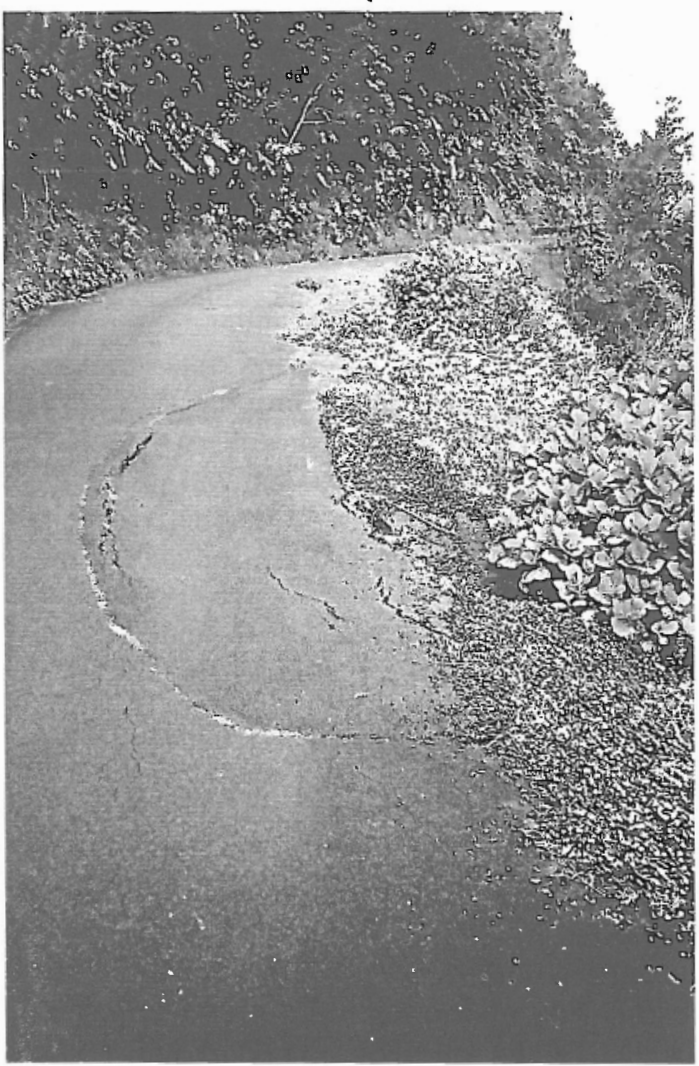

Fot. 6 - Início de fracturação do asfalto (proximidades da área do corte da estrada).

\section{O ponto da situação da Geografia Física no Brasil apresentado em livro}

\section{Fernando Rebelo}

Reflexões sobre a Geografia Física no Brasil (Rio de Janeiro, Bertrand Brasil, 2004, 280 p.) é o título de um livro organizado por António Carlos Vitte e António José Teix cira Guerra, professores de Geografia nas Universidades Estadual de Campinas (UNICAMP) e Federal do Rio de Janeiro (UFRJ), respectivamente.

Conforme se pode ver, desde logo, no Sumário (p. 5-9), trata-se de um conjunto de oito capítulos independentes escritos por doze especialistas, devidamente apresentados logo a seguir ao prefácio assinado por Adilson Abreu.

Todas as áreas tradicionais da Geografia Física são tratadas neste livro.

Um primeiro capítulo sobre "Os fundamentos teóricos da Geomorfologia e a sua influência no desenvolvimento das Ciências da Terra", da autoria de António Carlos Vitte, doutor em Geografia Física pela Universidade de São Paulo (USP), transporta-nos ao século XIX e à importância que o filósofo americano pragmatista Charles S. Pierce teve para aqueles que foram considerados os primeiros geomorfólogos - Karl G. Gilbert e William Morris Davis. O pragmatismo, que o autor, citando o próprio Pierce, considera ter tido as suas origens na Grécia Antiga, continua claramente a comandar o modo com conduzimos hoje as nossas investigações.

O segundo capitulo, escrito por António Carlos Tavares, também Doutor em Geografia Física pela Universidade de São Paulo(USP), refere-se a "Mudanças climáticas", documentando bem toda a problemática e mostrando uma síntese das que são projectadas e de algumas das suas consequências ambientais e socioeconómicas, de acordo com os Relatórios de 1997 e 2001 do Intergovernmental Panel on Climate Change (IPCC). Tudo girando em torno da química da poluição, 
com base em comparações de dados meteorológicos dos últimos cem anos ou pouco mais, as previsões catastróficas são assustadoras. Não parece, todavia, que os cientistas responsáveis por aqueles Relatórios se tenham preocupado muito com os motivos que, em tempos históricos, deram à Terra épocas bem mais quentes do que as actuais, sem que a poluição existisse, ou com os que, pelo contrário, originaram períodos tão frios que criaram calotes de gelo imensas e fizeram aparecer glaciares em tantas montanhas que hoje nem sequer têm cobertura de neve durante todo o Inverno. As razões de ordem cósmica que estarão certamente relacionadas com as mudanças climáticas, entre as quais a própria actividade solar que começa a ser cada vez melhor conhecida, não são equacionadas. Mas o capítulo em causa faz pensar, muito especialmente, nas consequências que os aumentos de temperatura têm nas grandes cidades.

Anderson Christofoletti, doutor em Geociências e Meio Ambiente pela UNESP - Rio Claro, é o autor do terceiro capítulo, intitulado "Sistemas dinâmicos: as abordagens da teoria do caos e da geometria fractal em Geografia", que nos dá uma nova visão teórica para abordagem aos velhos objectos de estudo geográfico.

"Biogeografia: natureza, propósitos e tendências" é o titulo do quarto capítulo, assinado por Adler Viadana, Doutor em Geografia Física pela USP, que trata de aspectos teóricos da especialidade, procurando a exemplificação com um caso de estudo na bacia do Rio Corumbataí, no Estado de São Paulo.

Lívia de Oliveira, Doutora em Geografia pela UNICAMP, e Lucy Machado, Doutora em Organização do Espaço pela UNESP - Rio Claro, escreveram o quinto capítulo - "Percepção, cognição, dimensão ambiental e desenvolvimento com sustentabilidade". Muito do que se salienta neste capítulo é já da área dos riscos, particularmente, dos chamados riscos ambientais. Falando do tema, com frequência, a nível global, as autoras aproximam-se, por vezes, do que foi já tratado no segundo capítulo, mas acrescentam exemplos concretos e muito variados de processos naturais ou acidentes tecnológicos que tiveram, ainda têm ou virão a ter consequências nefastas. Sem o dizerem, apontam as vulnerabilidades que tornam maiores os riscos ambientais - a pobreza e as dificuldades de acesso à saúde ou à educação.

Os riscos naturais como normalmente os entendemos, começam a aparecer no sexto capítulo, "Bacia hidrográfica e qualidade ambiental", da autoria de Rosangela Botelho, Doutora em Geografia Física pela USP, e António Soares da Silva, Mestre em Geografia pela UFRJ. A ligação entre as bacias hidrográficas e a vegetação que apresentam, a agricultura ou a falta dela, as diferentes espécies vegetais, tal como a relacionação com as perdas de solo ou de água consoante o tipo de uso, lançam a discussão sobre muitos problemas de riscos de erosão acelerada ou de riscos de acção de produtos químicos. Sem se colocarem numa perspectiva de estudo de riscos, os autores mostram, até com fotografias, como remontam "voçorocas" (barrancos de grande dimensão), como se depositam enormes quantidades de sedimentos em áreas de intervenção humana.

Muito mais directo em termos de riscos naturais, o capítulo sétimo, assinado por dois professores de Engenharia Civil, Cláudio Amaral e Rogério Feijó, intitula-se "Aspectos ambientais dos escorregamentos em áreas urbanas". Após uma breve introdução os autores falam de um "inventário de escorregamentos urbanos do Rio de Janeiro", para logo a seguir apresentarem as suas características, tratarem da sua localização pela cidade, mostrarem a sua tipologia e magnitude e se referirem às suas consequências socioeconómicas. Vem depois a "análise dos condicionantes ambientais nos escorregamentos no Rio de Janeiro", feita segundo um escalonamento histórico das principais ocorrências e com ilustração através de fotografias elucidativas. A "gestão de riscos de escorregamentos nos grandes centros urbanos" centrase também na área do Rio e é igualmente servida por boas fotografias. Entre muitas outras coisas, ficamos a saber que "os índices críticos utilizados no momento pela GEO-Rio, para eventos catastróficos são de 50 mm de chuva acumulada em 1 hora e de $175 \mathrm{~mm}$ de chuva acumulada em 24 horas" (p. 217) ou que "no Rio de Janeiro, 1663 boletins de escorregamentos permitem acompanhar, ao longo de 63 anos as modificações de características e do grau de influência dos factores deflagradores nos acidentes das encostas". J. ROSS (2001) e J. B. CONTI (2002) escreveram sobre alguns destes aspectos.

O oitavo e último capítulo é da responsabilidade de António José Teixeira Guerra, Doutorem Geografia pela Universidade de Londres, e Jane Mendonça, Licenciada em Geografia pela Universidade Federal do Maranhão (UFMA) - "Erosão dos solos e a questão ambiental". Com uma boa fundamentação teórica, vêm depois exemplos colhidos pelo território brasileiro, tanto em áreas urbanas, como em áreas rurais sobre "voçorocas" nos mais diversos estados de desenvolvimento. Uma ou outra comparação com países da Europa dita setentrional parece deslocada, mas a análise das características de um grande número de "voçorocas" permite aos autores a proposta de muitas medidas para evitar o avanço da erosão dos solos através deste processo. As nossas ravinas são muito pequenas (F. REBELO, 1994) quando comparadas com estas formas tão típicas dos países tropicais (I. AMARAL, 2002), mas as propostas para as evitar ou para lhes atenuar as consequências são por vezes as mesmas. 
Convirá, ainda, dizer que cada capítulo tem a sua bibliografia própria, quase sempre com grande número de espécies publicadas no Brasil, o que dá uma boa imagem da Geografia Física brasileira. Além disso, um índice remissivo de 12 páginas completa de modo muito útil este livro que merece bem ser conhecido dos geógrafos portugueses.

\section{Referências bibliográficas}

AMARAL, Hídio do (2002) - "Luanda e os seus dois arcos complexos de vulnerabilidade e risco: o das restingas e ilhas baixase o das escarpas abarrocadas". Territorium, 9, p. 89-115.
CONTI, José Bueno (2002) - "Riscos naturais na região tropical brasileira". Territorium, 9, p. 117-122.

REBELO, Fernando (1994) - "Do ordenamento do território à gestão dos riscos naturais. A importância da Geografia Física salientada através de casos de estudo seleccionados em Portugal". Territorium, 1, p. 7-15.

ROSS, Jurandyr Luciano Sanches (2001) - "Inundações e deslizamentos em São Paulo. Riscos da relação inadequada sociedadenatureza". Territorium, 8, p. 15-23.

\section{Riscos naturais e ordenamento na Europa}

\section{Fernando Rebelo}

Primeiro, o Colóquio Internacional (cfr. F. REBELO, 2003), um anoe meio depois, o livro. Não propriamente um livro de actas, mas um livro que, como se diz logo a abrir, "retoma as comunicações apresentadas quando do colóquio no Grande Arco da Defense, 22-24 de Outubro de 2002".

Risques Naturels et Aménagement en Europe, obra publicada sob a direcção de Yvette Veyret, Gérald Garry e Nancy Meschinet de Richemond (Paris, Armand Colin, 2004, 254 p.) aparece-nos com 21 capítulos organizados em três partes - "La France", "L'Europe" e "Une Europe des Risques" - e termina com uma conclusão assinada pelos três responsáveis. Alguns capítulos são grandes, na medida em que desenvolvem comunicações apresentadas; outros são pequenos, porque se limitam a reproduzi-las. Mas alguns títulos foram modificados.

Sobre a temática em causa relativamente a França há sete capítulos tratando de assuntos tão diversos como a política de prevenção dos riscos (abordada de vários modos por diversos autores), a cartografia dos riscos naturais (Gérald Garry et al.) ou as vulnerabilidades (André Dauphiné). No respeitante ao resto da Europa, são nove os capítulos igualmente variados quanto aos temas escolhidos, mas recaindo sobre oito países - Reino Unido (embora só Inglaterra e País de Gales), Suiça, Itália, Grécia, Portugal, Espanha, Hungria e Roménia. A gestão de riscos de vários tipos e a legislação sobre esta matéria dominam na maior parte dos nove capítulos, mas o caso particular da cartografia do risco de movimentos de terreno no Tirol do Sul (Mário Panizza e colaboradores) também não deixa de ser importante.

Os últimos cinco capítulos têm um carácter genérico e cabem perfeitamente na feliz designação dada pelos organizadores do livro à terceira parte. Fala-se de estratégias de investigação (Alfredo Lucia), de análise de riscos, de seguros, de integração no quadro da União Europeia, mas vai-se, por vezes, além dos riscos naturais.

A conclusão final salienta aspectos fundamentais que, comosempre em colóquios deste género, acabaram por revelar-se perturbadores. A terminologia considerada "muito héterogénea", torna-se particularmente confusa quando se trata de falar em vulnerabilidade. Também os mapas, em função da diversidade de escalas podem acarretar erros de localização ou mesmo nem dar a localização exacta de determinados riscos. Curiosamente, uma das questões de terminologia foi lançada por nós quando não demos o estatuto de risco maior aos sismos em Portugal continental e Madeira. Como deverão definir-se riscos maiores e riscos menores. Pela frequência da sua manifestação em crise? Pelo facto de se terem manifestado num passado já longínquo com características catastróficas? Quando quase todos os livros que tratam de riscos naturais falam mais ou menos demoradamente no terramoto de Lisboa de 1 de Novembro de 1755, dão a entender que o risco hoje é igual ao dessa época. Será que o nosso país é ainda aquele país? As regras da construção sísmica não terão contribuído para diminuir as vulnerabilidades? Será que nas áreas das construções antigas ainda vive tanta gente como naquela época? É evidente que no Algarve e na região de Lisboa o risco sísmico existe com muito mais importância do que no resto do país. Há que estar consciente desta realidade. E a Protecção Civil desde há anos que trabalha nesta área (F. REBELO, 1997). Mas não se pode olhar para o Algarve e para a região de Lisboa como se não tivesse havido grandes melhorias em termos de diminuição do risco sísmico relativamente ao risco existente no século XVIII. O mesmo não se 